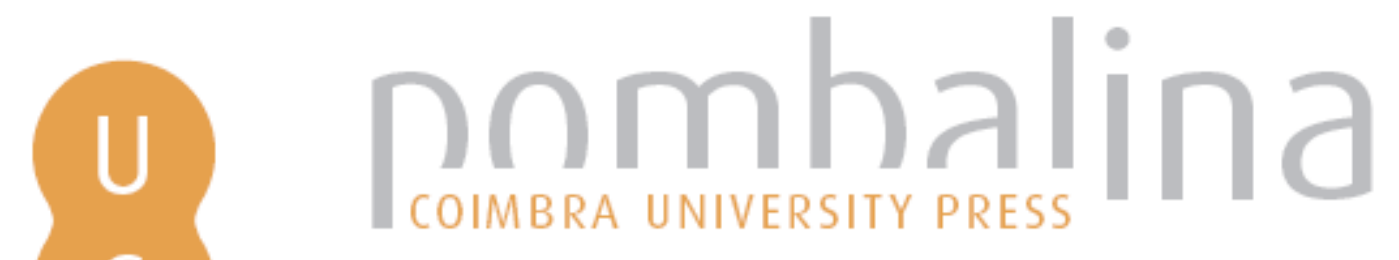

\title{
Federação Russa
}
Autor(es):
Freire, Maria Raquel
Publicado por: Imprensa da Universidade de Coimbra
URL persistente:
URI:http://hdl.handle.net/10316.2/31209
DOI:
DOI:http://dx.doi.org/10.14195/978-989-26-0086-4_6

Accessed : $\quad$ 19-May-2017 17:28:03

A navegação consulta e descarregamento dos títulos inseridos nas Bibliotecas Digitais UC Digitalis, UC Pombalina e UC Impactum, pressupõem a aceitação plena e sem reservas dos Termos e Condições de Uso destas Bibliotecas Digitais, disponíveis em https://digitalis.uc.pt/pt-pt/termos.

Conforme exposto nos referidos Termos e Condições de Uso, o descarregamento de títulos de acesso restrito requer uma licença válida de autorização devendo o utilizador aceder ao(s) documento(s) a partir de um endereço de IP da instituição detentora da supramencionada licença.

Ao utilizador é apenas permitido o descarregamento para uso pessoal, pelo que o emprego do(s) título(s) descarregado(s) para outro fim, designadamente comercial, carece de autorização do respetivo autor ou editor da obra.

Na medida em que todas as obras da UC Digitalis se encontram protegidas pelo Código do Direito de Autor e Direitos Conexos e demais legislação aplicável, toda a cópia, parcial ou total, deste documento, nos casos em que é legalmente admitida, deverá conter ou fazer-se acompanhar por este aviso.

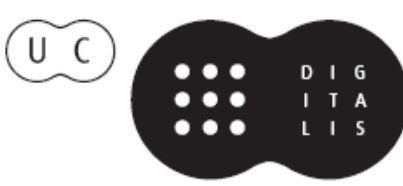


Política Externa As Relações Internacionais em Mudança

$\frac{\mathrm{I}}{\mathrm{U}}$ 


\section{CAPÍtuLO 6}

\section{FEDERAÇÃO RUSSA}

Este capítulo traça as principais linhas de política externa da União das Repúblicas Socialistas Soviéticas (URSS) e depois da Federação Russa, identificando linhas de decisão e actuação em contextos diferenciados que se revelam fundamentais para a compreensão das suas dinâmicas de política externa. O texto segue um alinhamento histórico dado o processo de transição que a desagregação da URSS pressupôs e as implicações em matéria de política externa que o final da Guerra Fria e a redefinição geográfica, política e socioeconómica da Rússia exigiram.

\section{Processo de formulação e decisão em política externa: centralismo} e autoridade

Na URSS o processo de formulação e decisão de política externa estava concentrado nos líderes do Partido Comunista, sendo que o governo apenas ratificava as decisões aí tomadas, conferindo-lhes legitimidade. O papel dos líderes foi sempre fundamental na União Soviética e na Rússia pós-soviética dado o carácter dirigista do sistema, como analisado. O contexto de Guerra Fria e o modelo ideológico de base à política Marxista-Leninista condicionavam fortemente a política externa, bem como as políticas domésticas, assentes em princípios de centralismo e autoridade. O centralismo dirigista inerente ao modelo permitia um processo de decisão e implementação 
unificado, prosseguindo o interesse da União num cenário de nenhuma abertura a críticas ou pressões anti-linha do Partido. A militarização da Guerra Fria constituiu um factor determinante na orientação das políticas do país no contexto bipolar. Com o final da Guerra Fria a política externa altera-se radicalmente dada a alteração profunda quer a nível interno, com a desagregação do bloco soviético e a redimensionação da área pós-soviética, quer externo, com o final da bipolaridade que havia caracterizado a ordem internacional por mais de cinco décadas. A nova Constituição da Federação Russa institucionaliza as principais competências em matéria de política externa no presidente, apoiado por uma estrutura burocrática, onde as elites vão alcançar influência substancial.

A política externa russa é essencialmente da responsabilidade do presidente, incumbido da definição das linhas de actuação de base subjacentes ao posicionamento da Federação Russa nos assuntos internacionais (The Constitution of the Russian Federation, 1993, art.80). O executivo está encarregue da implementação da política externa (ibid, art.114), sob supervisão presidencial, especialmente no contexto de governação centralizada existente. De facto, este é um dos elementos de continuidade mais vincado, a par do peso histórico da 'grande Rússia', como factor determinante na orientação das suas políticas.

A institucionalização do ruling vertical (autoridade vertical), termo cunhado pelas elites russas para designar um sistema de governo hierárquico assente em princípios de subordinação e num papel de domínio do ramo executivo (Shevtsova, 2005: 7), com apoio da elite política próxima do Presidente, tem assegurado controlo político e social na Rússia pós-soviética. Os lobbies económicos e na área da segurança e defesa, essencialmente, têm-se confundido nos meandros dos grandes grupos económicos estatizados ou quasi-estatizados. Quanto a grupos de pressão e opinião, estes têm tido expressão limitada num contexto de governação centralizada, onde o activismo cívico se mantém sob escrutínio apertado das autoridades. De facto, o controlo de actividades e vozes dissidentes, práticas comuns nos tempos dos czares e sob o regime Soviético, são nos dias de hoje comuns na Rússia. "A Rússia é ainda melhor explicada por uma rede de relações clientelistas e patrimonialistas. Esta é uma das razões pelas quais a Rússia 
pós-Soviética tem tanta dificuldade em gerar o seu próprio sentido de comunidade cívica» (Hosking, 2003: 10).

O processo de construção identitária ainda em curso na Rússia, e cujas influências europeias e asiáticas são historicamente conhecidas, tem marcado a própria delineação da política externa, onde a tensão entre as dimensões ocidental e oriental tem sido visível, em particular no período pós-Guerra Fria. A consubstanciação da identidade russa pós-soviética passa não só pela linhagem sociológica europeia ou asiática, mas também pela identificação ideológica já não soviética de orientação comunista, mas também não democrática no entendimento ocidental, o que tem implicado o desenho de uma identidade muito própria - uma nova identidade num contexto diferenciado. As divisões internas na Rússia, com os Euro-Atlantistas a favorecer ligações mais próximas aos Estados Unidos da América e Europa, os Eurasianistas a olharem o cenário a leste para alianças estratégicas, incluindo a China e Índia, e a estratégia nacionalista a centrar-se no quadro interno, procurando a afirmação do poder russo com base no legado imperial do país, na sua força política, influência e recursos económicos, mostram, de forma simplificada, a multi-dimensionalidade do discurso de política externa (ver Porter, 1996: 121; Lowenhardt, 2000: 167-174).

Deste modo, a política externa, bem como as políticas internas, conjugam-se numa lógica de articulação multi-nível, com heranças importantes e padrões de formulação e decisão de política externa que se vão ajustando quer a contextos quer a momentos, como analisado nas próximas secções.

\section{O período soviético}

Os primeiros anos da Guerra Fria foram marcados por uma crescente desconfiança entre os dois blocos, prosseguindo políticas de desenvolvimento assentes em pressupostos antagónicos: o capitalismo ocidental versus o comunismo soviético. Além do mais, eram notórios os esforços de salvaguarda de influências externas de áreas de interesse, em particular no que toca a Europa Central e de Leste, definida como central na estratégia hegemónica soviética, que entendia a presença dos EUA na Europa como uma ameaça às 
suas ambições. O factor ideológico tornou-se um elemento fundamental nas políticas soviéticas, expresso em políticas sociais, económicas e de segurança, revelando o carácter co-constitutivo das dimensões doméstica e externa. As acções de Estaline contra movimentos comunistas alternativos, como na China e Jugoslávia, constituem sinal da ameaça que a instabilidade externa podia causar, bem como um reconhecimento das fragilidades do bloco soviético, incluindo em termos económicos. Isto resultou na redução de contactos com o mundo ocidental, e proporcionou uma postura fechada e introspectiva, melhor capaz, de acordo com Estaline, de responder à necessidade de projecção de uma imagem de força da União Soviética, independentemente dos seus problemas internos. E, neste contexto, o desenvolvimento de capacidades militares e o redireccionamento de recursos económicos para o esforço de militarização eram ilustrativos da estratégia de afirmação no contexto bipolar. Além do mais, em finais dos anos 1940, as acções soviéticas manifestavam já a sua vontade de manter controlo sobre uma área alargada, bem para além dos estados satélite. A Guerra da Coreia (1950-1953) é disso exemplo, com a máquina ideológica soviética a fornecer incentivos para a ofensiva de Ho Chi Minh na Indochina contra os franceses. Estas acções faziam parte de um entendimento mais lato de que a angariação de apoios para a causa ideológica conferiria poder e estatuto adicional à URSS na sua lógica de afirmação e expansão global. Estaline apoiou o líder da Coreia do Norte Kim Il Sung nos seus esforços de fortalecer o controlo da República Democrática da Coreia e eventualmente alargar o seu poder à República da Coreia (sul), deste modo fazendo pressão sobre a área de influência norte-americana. O resultado deste envolvimento não foi bem sucedido, e as lições aprendidas desta experiência demonstraram a verdadeira possibilidade de confrontação armada entre dois grandes poderes nucleares, mas também que os seus líderes podiam optar pela contenção (Gaddis, 2005: 61).

O mandato de Khrushchev, que se sucede a Estaline, com o prosseguimento da 'des-Estalinização' vai marcar um novo curso na política soviética, com início em 1956, contra o 'culto da personalidade' e os procedimentos internos de colectivização forçada. Isto significou uma nova direcção nas políticas soviéticas que implicou não só a definição de novos objectivos económicos, mas também uma abordagem política diferenciada resultante 
também do posicionamento pós-Coreia. Esta nova abordagem definiu a "Coexistência pacífica» como o reconhecimento da capacidade de destruição nuclear mútua (Sakwa, 1998), e o entendimento de que o conflito violento entre capitalismo e comunismo deveria ser substituído por confrontação económica e ideológica. O objectivo soviético era alcançar e ultrapassar o poderio económico norte-americano nos anos 1980, o que lhe permitiria prosseguir o objectivo ideológico de expansão comunista.

Procurando contrapor o poder e influência do bloco ocidental, em Maio de 1955 foi criada a Organização do Pacto de Varsóvia como contrapeso à Aliança Atlântica (OTAN). Esta estrutura militar centrada na União Soviética, incluía estados satélite como a Albânia, Bulgária, Checoslováquia, Hungria, Polónia e Roménia. Seguia uma estrutura de comando unificada sob controlo de Moscovo, e tornou-se uma extensão das forças militares soviéticas na sua área de influência de modo a desempenhar funções várias, incluindo o monopólio incontestado sobre as forças do Pacto, competição relativa quanto à representatividade militar dos estados membros, e legitimação da presença de tropas soviéticas nos territórios dos estados membros do Pacto. A criação desta estrutura também pretendeu enviar um sinal ao bloco ocidental relativo às capacidades militares soviéticas, enquanto simultaneamente procurando uma resposta estrutural aos receios da URSS relativamente a perda de controlo face a dinâmicas de contestação internas, incluindo centralização económica, comando militar e estratégias de controlo. Esta tensão sublinha as dificuldades enfrentadas no seio do bloco, mas é também reveladora da forma como os líderes soviéticos entendiam estas como limitando a sua capacidade para actuar globalmente.

Contudo, a década de 1950 foi marcante em termos científicos e tecnológicos. Neste período é registado o desenvolvimento da primeira bomba termo-nuclear, de mísseis balísticos inter-continentais, e de tecnologia espacial avançada com o lançamento do Sputnik, o primeiro satélite artificial. Estes avanços tecnológicos, apesar dos vários falhanços das experiências de colectivização e da excessiva concentração na produção industrial pesada, conferiram à liderança soviética confiança para prosseguir um papel activo dentro e fora da sua área de influência. O sucessor de Khrushchev, Leonid Brejnev, cunhou a denominada Doutrina Brejnev, espelhando esta realidade 
de um envolvimento mais activo. A União Soviética actuaria face a qualquer tentativa de minar o poder central de Moscovo, fosse através de tentativas de mudança revolucionária do regime ou quaisquer esforços para abandonar o bloco (Checoslováquia, Hungria e Polónia, ver d'Encausse, 1983: 159-218). Deste modo, e apesar do registo de autonomia constante dos estatutos da União, os estados do bloco não poderiam desafiar a liderança em termos ideológicos ou materiais, nem a abordagem soviética centralizada à governação das diferentes regiões. A doutrina foi alargada para além dos estados satélite, como demonstrado na intervenção soviética no Afeganistão em 1979. Contudo, Moscovo confrontou-se com uma China desconfortável com a leitura ideológica soviética, resultando em interpretações diferenciadas da via para o comunismo, e no diferendo ideológico sino-soviético de finais da década de 1950, inícios dos anos 1960.

A União Soviética procurou reposicionar o seu estatuto de grande potência na década de 1970 após problemas no seio do bloco e a tensão que marcou a década de 1960, com a construção do Muro de Berlim, e em particular a crise dos mísseis de Cuba (1962). A elevada tensão resultante da crise chamou a atenção para a necessidade de uma nova estratégia face ao reconhecimento da destruição mútua assegurada, e a insegurança associada a esta capacidade militar deu lugar ao diálogo, que por seu turno permitiu passos concretos na negociação de acordos de limitação de armamento. Exemplos incluem o Tratado de Interdição Parcial de Testes Nucleares (1963), o Tratado de Não-Proliferação de Armas Nucleares (1968), e o Acordo de Limitação de Armas Estratégicas (1972), que iniciou as conversações SALT (Strategic Arms Limitation Talks). Estes desenvolvimentos são ilustrativos de dois aspectos fundamentais: por um lado, a necessidade de condições domésticas favoráveis para avançar os objectivos de política externa, sublinhando o reconhecimento da parte dos líderes soviéticos da existência de constrangimentos internos; e por outro, o entendimento de que para manter o reconhecimento internacional desejado, a URSS precisava abrir-se e demonstrar capacidade de diálogo face ao exterior, de modo a alterar a sua imagem de poder iliberal.

Neste contexto de détente, em 1975 foi assinada a Acta Final de Helsínquia que estabeleceu a Conferência sobre Segurança e Cooperação na Europa (CSCE) 
(HFA, 1975). O objectivo deste organismo político era fomentar o diálogo entre os dois blocos, com contactos diplomáticos a alcançar um nível substancial na altura, e permitindo um fórum de contacto que apesar da sua estrutura informal e das suas reuniões com periodicidade indeterminada, fazia a ponte entre o leste e o ocidente. Mas rapidamente o contexto se deteriorou e na década de 1980 não houve cimeiras bilaterais URSS-EUA, estes últimos não participaram nos Jogos Olímpicos de Moscovo de 1980 e, em 1984, foi a vez dos soviéticos boicotarem a sua participação nos Jogos de Los Angeles. Em meados da década de 1980, não só os conflitos políticos se adensavam, mas também a situação da economia soviética se tornava insustentável. A guerra no Afeganistão, desfavorável aos soviéticos, ainda pressionou mais recursos parcos: «entre 1986 e 1990 o défice enquanto parte do PIB da União Soviética oscilava entre $5.7 \%$ e 9.1\%, atingindo 12-14\% em 1991" (Kaufman e Hardt, 1993: 47). A conjugação de vários factores apontava para a necessidade de reformas estruturais, que Gorbachev encabeça e cujo desfecho, para além do esperado, leva à desagregação da URSS e ao fim da rivalidade bipolar.

\section{A política externa em transição e a delineação da nova Rússia}

Mikhail Gorbachev foi um político central na transformação da União Soviética após o desencanto dos anos de Leonid Brezhnev, e das curtas lideranças de Yury Andropov e de Konstantin Chernenko (1982-1985). Gorbachev concentrou-se no processo de mudança que entendia como necessário à modernização e crescimento da URSS (Sakwa, 1998: 72, 7576). Contudo, as políticas da reestruturação (perestroika) da economia, de aceleração (uskorenie) e de abertura (glasnost), indicando um curso reformista que visava a transformação política e o desenvolvimento económico, quer a nível interno quer na política externa, não foram capazes de alterar práticas profundamente enraizadas, afastando-se dos seus objectivos iniciais.

A política externa de Gorbachev reflectia o seu curso reformista a nível interno, acompanhado pela vontade de aproximação ao ocidente, em termos externos. Esta política de aproximação ao ocidente foi expressa em medidas concretas, como a assinatura em Dezembro de 1987 com os EUA do Tra- 
tado sobre Forças Nucleares de Alcance Intermédio; o anúncio da retirada soviética do Afeganistão em 1988; e uma política de abertura e proximidade ao leste. Internamente, qualificou o sistema económico socialista e o papel de gestão política operado pelo Partido Comunista como desadequados à nova realidade que a União experimentava.

Pôs assim em marcha os princípios da dimensão humana contidos na Declaração de Helsínquia de 1975 (incluindo, por exemplo, a promoção de liberdades civis e discussão pública), encontrando no entanto oposição do aparelho burocrático que claramente entendia estas medidas como ameaça à sua autoridade e poder, agravado pelos movimentos nacionalistas que por todo o espaço pós-soviético exigiam independência. Contudo, revelou-se tarefa difícil operacionalizar as reformas estruturais profundas a nível político e económico necessárias à consolidação do crescimento no seio da União. Como acelerador deste processo, Gorbachev procurou consolidar o seu poder, para que a sua capacidade de decisão e implementação fosse reforçada, mas foi incapaz de desenvolver a maior parte dos seus projectos reformistas face à crescente resistência com que se deparava - o aparelho do partido permaneceu um forte desafiador da perestroika.

No entanto, e apesar destes obstáculos, Gorbachev conseguiu levar a cabo reformas político-administrativas fundamentais, como o estabelecimento do Congresso dos Deputados do Povo em 1989, sob a sua liderança, e com maior poder de decisão que o Soviete Supremo. De facto, foi eleito um novo Soviete Supremo pelo novo Parlamento e Gorbachev conseguiu aqui reunir amplo poder, permitindo terminar com o monopólio do Partido Comunista da União Soviética enquanto única organização política legal. Gorbachev permitiu uma política externa diferente, mais democrática para com o leste - especialmente os estados-satélite desde a Segunda Guerra Mundial -, bem como mais flexível relativamente às repúblicas constituintes da URSS. Estas mudanças profundas permitiram o fim da Guerra Fria e conduziram à queda da URSS. "Foi Gorbachev que simbolizou a transcendência das revoluções progressistas e que assim permitiu à Rússia o regresso às políticas 'normais', um tipo de políticas que não incluía uma fronteira emancipatória. O sujeito da emancipação acabou por não ser o povo no sentido dos sujeitos soberanos da democracia, mas uma elite 
transformadora guiada pelos princípios de liderança e modernização das elites para as populações»(Sakwa, 2005: 272).

A queda da URSS teve implicações várias no reordenamento a diferentes níveis que se seguiu. Tratou-se do fim de uma ideologia unificada sustentada em princípios Marxistas-Leninistas que permitiam coesão social; implicou a perda de identidade, agregada durante décadas sob a planificação e governação centralizada do Partido Comunista; pôs em marcha um processo de transição para um modelo de governação que a Rússia nunca antes havia experimentado; alterou fronteiras e exigiu redefinição de relações com uma vizinhança instável, lado a lado com a redefinição do papel e lugar da Rússia na Europa e no mundo. Este foi um processo de mudança complexo com impacto claro na definição de uma política externa diferenciada no contexto pós-Guerra Fria. A Federação Russa assumiu muitas das responsabilidades da extinta URSS, incluindo o controlo do arsenal nuclear soviético, bem como representações em fora internacionais, como as Nações Unidas, incluindo um lugar permanente no Conselho de Segurança.

Na Rússia da transição, a política externa reflectiu os constrangimentos que as políticas russas enfrentavam internamente. Muitas das dinâmicas até então reprimidas surgem agora de forma desarticulada, revelando os limites inerentes ao processo burocrático centralizado que havia vigorado durante décadas. O pluralismo associado ao modelo democrático em experimentação revelou-se sinónimo de pressão e desordem. A incapacidade de estruturação de princípios delineadores assentes em processos discutidos e plurais, acabou por levar à tendência de centralização dos processos de decisão e implementação de políticas, incluindo a política externa, e a um crescente autoritarismo, claramente visíveis na Rússia de hoje.

\section{A primeira década pós-Guerra Fria: Boris Ieltsin}

Boris Ieltsin chegou à política sob anuência de Gorbachev na altura em que o último se tornou presidente da URSS (1985). Apesar de uma trajectória sinuosa, em 1989 foi eleito para o Congresso dos Deputados do Povo e tornou-se mais tarde Presidente do Parlamento russo. Nesta altura, 
Ieltsin e Gorbachev prosseguiam objectivos incompatíveis, com o primeiro a enfrentar hostilidade interna para com medidas que se revelaram difíceis e não recompensadoras, e o último a criticar duramente Gorbachev por actuar lentamente na reforma do sistema, exigindo um ritmo mais acelerado e medidas mais resolutas. Face à situação de tensão vivida, agravada pela sucessão de declarações de independência de antigas repúblicas, foi convocado um referendo para aferir sobre o futuro da União enquanto federação de repúblicas soberanas igualitárias, cujo resultado foi favorável à preservação da URSS enquanto entidade agregadora, mas não aglutinadora, das diferentes repúblicas. Na Rússia uma outra questão foi colocada a escrutínio: se a eleição Presidencial se devia manter como processo selectivo e fechado, ou ao invés, decorrer a nível nacional com participação alargada das populações.

O referendo da União de Março de 1991 foi favorável a eleições presidenciais directas, que culminaram na vitória de Boris Ieltsin, marcando claramente o descontentamento generalizado com o processo de transição iniciado por Gorbachev. A tentativa falhada de golpe de estado em Agosto de 1991, criticando os falhanços da perestroika e glasnost, sinalizava então uma União Soviética fragmentada que oficialmente cessou a sua existência a 25 de Dezembro.

Dias antes, a 8 de Dezembro de 1991, foi criada a Comunidade de Estados Independentes (CEI) por um acordo assinado entre a Rússia, Bielorrússia e Ucrânia, com base no princípio da igualdade soberana dos seus estados membros. O objectivo era constituir um mecanismo agregador que permitisse continuidade nas unidades constituintes da União Soviética, agora sob uma nova designação. Contudo, a criação da CEI não evitou que as repúblicas seguissem o seu próprio curso, independentemente da sua adesão à nova organização. Actualmente, a CEI, bastante fragilizada no que toca o nível de coesão interna, é essencialmente um fórum de diálogo.

Eleito como a nova face da reforma, Ieltsin não foi bem sucedido no processo de transição democrática, tornando-se progressivamente dependente e ávido de poder, centralizando autoridade e deixando pouco espaço de manobra para visões alternativas em formação na nova Rússia. Apesar de acordo quanto ao pacote alargado de reformas necessárias, quer a nível institucional quer económico e social, a transição de um modelo de organização e desenvolvi- 
mento socialista, planificado e centralizado, não foi simples. A privatização de empresas russas, entendida como forma de invalidar o regresso a um sistema comunista, beneficiou essencialmente a elite próxima de Ieltsin. "Os velhos oficiais soviéticos apoiavam enfaticamente [Ieltsin] enquanto tomavam conta de bens públicos - desde o pequeno comércio à indústria petrolífera -, e se transformavam em capitalistas ao mesmo tempo que a inflação dizimava os rendimentos da população comum» (Daniels, 2008: 33). A nível externo, os críticos da postura europeísta promovida por Gorbachev apelaram a um enfoque da política externa na Eurásia, enquanto os nacionalistas pressionaram para a concentração das decisões políticas nas questões internas, para que a Rússia pudesse reunir condições económico-sociais e políticas essenciais à sua projecção externa de forma sustentada no que era definido como o seu «estrangeiro próximo», leia-se espaço pós-soviético.

Os primeiros anos de governação são conhecidos como período romântico quando boas relações com o ocidente são privilegiadas e é prosseguida uma política de não-ingerência no espaço pós-Soviético. A Doutrina Sinatra - «I'll do it my way» - permitiu às antigas repúblicas consolidarem o seu curso de independência, muitas das quais pela primeira vez, dado que apesar da autonomia que formalmente gozavam no quadro da União, esta equivalia na realidade a uma relação de submissão face ao poder central do Partido Comunista em Moscovo. A definição da Rússia como aliado natural da Europa será evidenciada na procura de integração em instituições ocidentais, solicitando a adesão ao Conselho da Europa (concretizada em Fevereiro de 2006), aderindo à Parceria para a Paz no contexto da OTAN (Junho de 1995), e aprofundando relações com a Comunidade Europeia, com base na assinatura do Acordo de Parceria e Cooperação (APC) de 1994 (apenas ratificado em 1997), a par do estreitamento de relações com Washington. No entanto, a esperada ajuda financeira internacional chegou tardiamente e revelou-se insuficiente, sendo que a condicionalidade associada acabou por gerar sentimentos anti-ocidentais e uma exigência interna de mudança, essencialmente promovida pelos grupos nacionalistas e comunistas. As críticas sobre a ingerência ocidental nos assuntos russos, em particular no que toca o tratamento das minorias russas fora do país (leia-se espaço pós-soviético), aumentaram o descontentamento e levaram as autoridades de 
Moscovo a adoptarem uma política mais interventiva. Note-se, no entanto, o cariz reactivo desta opção.

Na sequência destes desenvolvimentos, Ieltsin aprovou um novo conceito de política externa em Abril de 1993, reflectindo já o tom reactivo ao crescente desencanto com a opção ocidental e aos baixos benefícios resultantes dessa, levando à equação de democracia com caos, oportunismo e corrupção. A vizinhança próxima tornou-se foco de atenção de Moscovo, tendência esta que se manteve até aos nossos dias. Referências ao ex-espaço Soviético incluem o uso de expressões como «interesses vitalmente importantes», constituindo uma "primeira prioridade» e tornando-se de «importância fundamental», e reflectindo também uma política mais equilibrada entre ocidente e oriente.

... A Federação Russa, apesar da crise que atravessa, permanece uma grande potência em termos do seu potencial, da sua influência no curso dos acontecimentos mundiais e da responsabilidade que assume como resultado disso. É responsável não só pela nova ordem mundial que emergiu após o colapso do campo socialista, mas especialmente pela criação de um novo sistema de relações positivas entre os estados que faziam parte da União Soviética, oferecendo a garantia de estabilidade nestas relações (Foreign Policy Concept, 1993).

Mais tarde, em Novembro, Ieltsin anunciou o documento plasmando a nova doutrina militar russa, identificando as principais linhas de política militar, o cariz não ameaçador dos meios militares russos (nucleares e não nucleares), e a identificação de fontes de instabilidade existentes ou potenciais, bem como de eventuais ameaças. A doutrina afirma que os «interesses vitais da Federação Russa de modo algum colidem com a segurança de outros estados e são assegurados no quadro de relações interestaduais equitativas e mutuamente benéficas» (Russian Military Doctrine, 1993). O novo conceito de política externa e a doutrina militar reforçam o interesse nacional, a interconexão próxima entre a política e os militares, e a vontade de posicionar a Rússia enquanto actor fundamental nas relações internacionais.

A partir de 1993, e apesar das dificuldades associadas, o curso de reafirmação tornou-se claro na orientação política do Kremlin: reafirmar o papel 
da Rússia como actor influente, em particular em termos regionais. Este objectivo foi prosseguido através de influência e poder político, pressão político-económica e presença militar dissuasora no espaço pós-Soviético, para descontentamento de algumas destas repúblicas. Como garante da estabilidade na sua área de vizinhança, a Rússia assumiu-a como de interesse estratégico nacional onde ingerências externas não eram bem acolhidas. Desde 1995 esta abordagem consolidou-se, com a definição inicial de uma política externa multi-vectorial pelo Kremlin. Em meados dos anos 1990, a política externa russa encontrava-se traçada em torno de dois círculos principais: um círculo mais restrito revestido de primazia que incluía as repúblicas ex-soviéticas, e outro mais alargado, envolvendo o ocidente (Europa e EUA) e a Ásia, embora inicialmente não enquanto dimensões de relevância paralela, com a primeira a dominar a agenda. Até ao final da década pós-Guerra Fria esta tendência foi reforçada.

Após as eleições de 1995, Yevgeni Primakov, um líder pragmático, assumiu o Ministério dos Negócios Estrangeiros. Conhecido como o "Eurasianista», recalibrou a dimensão oriental como peça fundamental nos interesses de política externa russos. Procurou marcar também o descontentamento russo face a algumas políticas ocidentais, em particular a questão da OTAN. As relações tortuosas de maior ou menor proximidade ao ocidente, o relacionamento nem sempre fácil com as novas repúblicas independentes, e a prossecução do objectivo de reconhecimento da Rússia enquanto potência internacional marcaram os anos de Ieltsin, não pela sua capacidade de gestão de interesses e oportunidades, mas antes pela sua incapacidade de formulação e implementação de políticas coesas e claramente orientadas para os objectivos máximos da política externa russa, nomeadamente a promoção do interesse nacional.

\section{A política externa de Vladimir Putin e Dmitry Medvedev}

Enquanto presidente da Rússia entre 2000 e 2008, Putin definiu a política externa do país como multi-vectorial e multipolar. Os principais documentos adoptados no início do seu primeiro mandato sublinham o potencial desta- 
bilizador de uma «estrutura unipolar do mundo com o domínio económico e poder dos Estados Unidos», a CEI como área de importância estratégica e a dimensão leste (Ásia-Pacífico) como uma região relevante na política externa de Moscovo (National Security Concept 2000; Russian Military Doctrine 2000; Foreign Policy Concept 2000). Assim, a Rússia procura uma política externa equilibrada onde a procura de pólos múltiplos tem por objectivo diversificar aliados e permitir a alteração de relações privilegiadas numa procura constante de contra-peso e primazia. A fórmula multi-vectorial ganha nova dimensão com Putin.

O 11 de Setembro adicionou um novo elemento a este desenho da política externa: uma nova ordem internacional sob primazia dos Estados Unidos. Putin ofereceu o seu apoio à luta global contra o terrorismo, e as vozes críticas ocidentais face ao desrespeito pelos direitos humanos e liberdades fundamentais na Rússia, e em particular na República da Chechénia, foram quase silenciadas. Além do mais, a realização concreta de que a Rússia não podia fazer muito face a desenvolvimentos inevitáveis, como o alargamento da UE e da OTAN, levaram a que a Rússia alterasse o seu discurso. "As mudanças na política externa russa desde 11 de Setembro, assim, baseiam-se em cálculos de prioridade e interesse, onde o risco se distingue da ameaça e as necessidades reais estão separadas de falsas ambições» (Lynch, 2003: 29-30).

Com um olhar realista sobre o interesse nacional e as prioridades de política externa, o chamado "pragmatismo nacionalista" (Light, 2003: 48), a projecção de poder e curso afirmativo de Vladimir Putin assentam numa ordem interna estável e em crescimento económico derivado essencialmente das receitas do petróleo e gás natural. Como o Ministro dos Negócios Estrangeiros Sergei Lavrov afirmou, "a política externa russa hoje é tal que pela primeira vez na sua história, a Rússia está a começar a proteger o seu interesse nacional usando as suas vantagens competitivas» [geopolítica da energia] (RFE/RL, 2007). Contudo, o crescimento da Rússia entre 2000 e 2008 não escondeu as fragilidades que o país enfrenta face a um sistema económico demasiadamente dependente dos recursos energéticos, visíveis na crise do Outono de 2008. No entanto, um contexto interno favorável permitiu a Putin uma política externa assertiva no espaço CEI e para além deste, demonstrando o seu des- 
contentamento face a uma série de acontecimentos, como o alargamento da OTAN, o projecto de instalação de equipamentos relacionados com o escudo de defesa anti-míssil em território polaco e checo, ou as pressões da União Europeia para assinatura da Carta Energética, entendida como não coincidente com os interesses russos. A não renovação do APC no quadro das relações com a UE, e a retirada unilateral do Tratado sobre Forças Convencionais na Europa (Tratado CFE), são exemplo da demonstração de desagrado face a um conjunto de desenvolvimentos entendidos como hostis à projecção de poder e influência russos. Paralelamente, a consubstanciação da cooperação no âmbito da Organização de Cooperação de Xangai, com especial relevância para a China, incluindo a realização de vários exercícios militares, surge como factor de contenção da primazia norte-americana, não escondendo o mesmo tipo de exercício face à China. Formas várias de a Rússia prosseguir o seu curso de afirmação internacional, contestando de forma mais activa acções que entende como contrárias aos seus interesses. Uma postura mais assertiva a que Dmitry Medvedev vai dar continuidade.

A eleição de Dmitry Medvedev como presidente da Rússia (Março 2008), implicou linhas de continuidade aos alinhamentos de política externa definidos por Putin. Medvedev apresentou em Setembro de 2008 o que definiu como os cinco pressupostos de base que informam a política externa. Estes incluem o primado do direito internacional; uma ordem internacional multipolar, novamente sublinhando os limites da unipolaridade e o contra-peso à primazia norte-americana; uma política não confrontacionista e o não isolamento da Rússia através do prosseguimento de relações de amizade na Europa, EUA e com outros estados (note-se o contexto pós-guerra na Geórgia); a protecção dos cidadãos russos independentemente da localização das diásporas, mantendo o discurso nacionalista; e o reconhecimento de áreas de influência, nomeadamente as áreas de fronteira descritas como "regiões prioritárias» (Reynolds, 2008). Estes princípios estão expressos no documento de política externa de 2008, bem como têm tradução, num tom mais acutilante, na nova doutrina militar aprovada em Fevereiro de 2010 (Russian Military Doctrine, 2010; Foreign Policy Concept, 2008).

Medvedev trouxe ainda uma nova abordagem aos temas económicos. Uma mudança muito necessária, expressa numa política de diversificação 
de investimentos, e no desenvolvimento de outras áreas sectoriais (não-energéticas) de forma a ultrapassar uma excessiva concentração nos recursos energéticos. Esta excessiva dependência de um sector económico tornou a economia russa extremamente vulnerável, demonstrando a necessidade de ajustes estruturais para evitar flutuações inesperadas nos preços do petróleo e do gás, com consequências directas no desempenho e resultados da economia russa. Aliás, a política de investigação, inovação e desenvolvimento tecnológico tem sido referida como um novo vector na política externa russa, ao permitir não só a consolidação de desenvolvimentos internos, como também a promoção de cooperação com parceiros externos, em diferentes áreas sectoriais.

Estes princípios sintetizam as linhas fundamentais de política externa que se foram consolidando na Rússia pós-soviética, sublinhando no entanto questões fundamentais relativamente à guerra na Geórgia de Agosto de 2008, e em particular às leituras desta. A intervenção russa na Geórgia teve lugar num contexto internacional com contornos de dissensão claros, como referido. A Rússia aproveitou a oportunidade para demonstrar o seu descontentamento face a um conjunto de acções que descreveu como provocadoras, não só da parte da república da Geórgia, mas também e em grande medida, dos seus aliados ocidentais. Estas incluem, por um lado, um alinhamento de política externa na Geórgia pro-ocidental, reforçado após a revolução rosa, e cuja determinação sempre desagradou a Moscovo. Por outro lado, a possibilidade em discussão de alargamento da OTAN a países como a Geórgia e Ucrânia, os avanços do projecto de defesa anti-míssil e o bloqueio nas conversações para a renegociação do APC, com as discussões a seguirem um curso que a Rússia entende como contrário aos seus interesses, entre outros, pesaram na decisão. Com a intervenção armada na Geórgia, Moscovo demarcou as linhas relativas a áreas de influência e interferência, enfraquecendo uma Geórgia cujo curso pro-soviético de desalinhamento era há muito entendido como provocador; reforçando a sua política de contenção dos EUA na Eurásia; e sublinhando o seu reposicionamento no sistema internacional como grande potência. De facto, em 26 de Agosto de 2008, por decreto presidencial, Medvedev reconhece a independência das duas repúblicas, a Ossétia do Sul e a 
Abcázia, formalizando um status quo entendido como consonante com os interesses russos.

Apesar da radicalização da tensão nas relações com a Europa e os EUA após a intervenção armada na Geórgia, rapidamente as relações foram normalizadas quer nos contextos bilaterais quer no âmbito multilateral, com a retomada de conversações no quadro da UE relativamente a um novo documento refundador da parceria, quer no quadro da OTAN com a retomada das sessões do Conselho OTAN-Rússia. Esta normalização progressiva, enquadrada também na reset policy promovida pelo presidente Obama, tem dado lugar a um contexto mais favorável. A assinatura em Abril de 2010 do novo Tratado START, que vem substituir o Tratado de 1991, sobre redução de armas estratégicas, é demonstrativa de progresso. Os EUA e a Rússia combinados detêm cerca de $90 \%$ do arsenal nuclear mundial, pelo que o acordo relativo a uma redução nos arsenais nucleares, inspecções conjuntas e troca de informação, constitui um momento fundamental na construção de confiança. Apesar de pender ratificação, este é um primeiro passo de um longo caminho. A adicionar à dimensão nuclear, note-se que a anterior proposta de instalação de um escudo de defesa anti-míssil na Europa (Polónia e República Checa), como referido, foi revista pelo presidente Obama, que propõe a instalação de sistemas interceptores em navios de guerra norte-americanos no Mediterrâneo, com bases terrestres móveis eventualmente após 2015. Este será um tema debatido na Cimeira da OTAN em Lisboa, em Novembro de 2010, tendo sido a Rússia formalmente convidada a participar nas discussões. De novo, este tipo de entendimento e a presença do presidente russo na Cimeira da OTAN em Lisboa, constituem sinais de que a cooperação é possível, e de que certamente os discursos inflamados sobre uma nova guerra fria, acabaram mesmo por se revelar desajustados. No Outono de 2010, a política externa russa para com o ocidente segue linhas de cooperação, apesar de animosidade em temas difíceis, como mencionado, com espaço de diálogo aberto, sendo no entanto muito necessário assegurar que paralelamente a este aja também espaço para a transformação de percepções, pois só desse modo a consolidação das chamadas parcerias poderá assumir verdadeira substância. 


\section{Considerações finais}

A Rússia tem lutado internamente com ambiguidade, tentando lidar com uma evolução nas atitudes e um contexto doméstico e internacional mudado, enquanto procurando lidar com o seu passado histórico e as heranças de séculos de governação autocrática e estatuto imperial. Uma mistura de tendências que se revela nas actuações da Rússia, demonstrando as dificuldades que o estado tem enfrentado na definição da sua própria identidade, fundamental para justificar tendências, opções e atitudes. Estas dificuldades internas têm expressão a nível internacional. O curso afirmativo no cenário internacional é como o espelho da imagem doméstica da Rússia, de consolidação e afirmação de poder. As linhas de orientação de base da política externa russa pós-Guerra Fria têm-se pautado pela multi-vectorialidade, com a identificação de áreas prioritárias de actuação, e multipolaridade, na defesa de um sistema internacional multipolar onde a primazia dos EUA seja constrangida. O desejo de reconhecimento do seu estatuto enquanto grande potência tem estado na agenda, demonstrando a relevância e peso da história não só naquilo que a Rússia é hoje, mas também naquilo a que a Rússia aspira, quer em termos de consolidação doméstica, quer relativamente à sua projecção a nível internacional.

\section{Questões para análise}

De que forma o papel dos líderes tem condicionado/projectado a política externa soviética/russa?

Analise o binómio ideologia/pragmatismo na política externa soviética e russa.

Face a um espaço pós-soviético heterogéneo onde se jogam políticas muito diferenciadas, argumente quanto ao poder e influência russos actuais no espaço da Comunidade de Estados Independentes (CEI).

Rússia entre leste e oeste: gestão comprometida de interesses? Comente a política externa russa de Putin para com a União Europeia e os Estados Unidos/Aliança Atlântica (OTAN). 


\section{Fontes na internet}

Carnegie Moscow Center, http://www.carnegie.ru/?lang=en

Ministério da Defesa, http://www.mil.ru/eng/

Ministério dos Negócios Estrangeiros da Federação Russa, http://www. mid.ru/brp_4.nsf/main_eng

Presidente da Rússia, http://eng.kremlin.ru/

The Moscow Times, http://www.themoscowtimes.com/index.php

\section{Leituras recomendadas}

Brown, Archie (2001) (org), Contemporary Russian Politics: A Reader. Oxford: Oxford University Press.

Freire, Maria Raquel; Kanet, Roger E. (2010) Key Players and Regional Dynamics in Eurasia: The Return of the 'Great Game'. Basingstoke: Palgrave MacMillan.

Levgold, Robert (2007) (org) Russian Foreign policy in the $21^{\text {st }}$ Century and the Shadow of the Past. New York: Columbia University Press.

Sakwa, Richard (1998) Soviet Politics in Perspective. $2^{\mathrm{a}}$ ed. London: Routledge.

Shevtsova, Lilia (2007) Russia Lost in Transition: The Yeltsin and Putin Legacies. Washington, D. C.: Carnegie Endowment for International Peace.

Tinguy, Anne (2008) (org) Moscou et le Monde - L'Ambition de la grandeur: Une Illusion?. Paris: Éditions Autrement.

\section{Bibliografia}

Blagov, S. (2004) "Putin Aims for Higher Russian Profile», PINR-Power and Interest News Report. [www.pinr.com/report.php?ac=view_report\&report_id=139\&language_id=1].

Daniels, Robert (2008) "From Gorbachev to Putin», The Nation, 20 de Outubro.

D'Encausse, Helene Carrere (1983) Le grand frere: l'Union Sovietique et l'Europe sovietisee. Paris: Flammarion.

Foglesong, D. and Hahn, G. (2002) «Ten Myths about Russia: Understanding and Dealing with Russia's Complexity and Ambiguity", Problems of Post-Communism, 6, 5-16. 
Foreign Policy Concept (2000) Foreign Policy Concept of the Russian Federation, Approved by the President of the Russian Federation V. Putin, 28 de Junho.

Foreign Policy Concept (2008) Foreign Policy Concept of the Russian Federation, Approved by the President of the Russian Federation Dmitry Medvedev, The Foreign Policy Concept of the Russian Federation, President of Russia Official Web Portal, 12 de Julho.

Freire, Maria Raquel (2007) «Triangulating Power: Russia, Europe and the United States Security Policies and Interests Projection in a Globalizing World", in Ioannis Stivachtis (org.), International Order in a Globalizing World. Aldershot: Ashgate.

Gaddis, J. L. (2005) The Cold War: A New History. New York: The Penguin Press.

Haas, Marcel de (2006) "Russia-China security cooperation", PINR-Power and Interest News Report, 27 de Novembro.

HFA (1975) Helsinki Final Act, Conference on Security and Co-operation in Europe Final Act. [http://www.osce.org/documents/mcs/1975/08/4044_en.pdf].

Hosking, Geoffrey (2003) Russia and the Russians: A History. Harvard: Belknap Press.

Ivanov, Aleksandr (2006) «Russia's Asian Face», International Affairs, A Russian Journal of World Politics, Diplomacy and International Relations, 52(2), 54-59.

Ivanov, Igor (2003) Minister for Foreign Affairs of the Russian Federation, "A New Foreign Policy Year for Russia and the World", International Affairs, A Russian Journal of World Politics, Diplomacy and International Relations, 49(6), 33-38.

Kapila, Subhash (2006) "Russia's Foreign Policy in a Resurgent Mode: An Analysis», Paper 1682, South Asia Analysis Group, 19 de Janeiro.

Katz, Mark N. (2006) "Primakov Redux? Putin's Pursuit of 'Multipolarism' in Asia», Demokratizatsiya, 14(1), 144-152.

Kaufman, Richard F. e Hardt, John P. (org) (1993) The Former Soviet Union in Transition. Ney York: M.E.Sharpe.

Light, Margot (2003) "In search of an identity: Russian foreign policy and the end of ideology", Communist Studies and Transition Politics, 19(3), 42-59.

Lowenhardt, John (2000) "Russia and Europe: Growing Apart Together», The Brown Journal of World Affairs, VII(1), 167-174.

Lynch, Dov (2003) «Russia Faces Europe», Chaillot Papers, 60. Paris: Institute for Security Studies.

Margelov, M. (2006) "Russia and the US: Priorities Real and Artificial", International Affairs, A Russian Journal of World Politics, Diplomacy and International Relations, 52(1), 23-30.

Page, Jeremy (2007) "Giants meet to counter US power», Times Online, 15 de Fevereiro. [www. timesonline.co.uk/tol/news/world/us_and_americas/article1386812.ece].

Pant, Harsh V. (2004) "The Moscow-Beijing-Delhi 'Strategic Triangle': An Idea whose Time May Never Come», Security Dialogue, 35(3), 311-328.

Porter, Bruce (1996) "Russia and Europe after the Cold War: The Interaction of Domestic and Foreign Policies", in Celeste Wallander (org.), The Sources of Russian Foreign Policy after the Cold War. The John M. Olin Critical Issues Series. Boulder, Colorado: Westview Press.

Reynolds, Paul (2008) "New Russian world order: the five principles», BBC News, 1 de Setembro.

"Russia: Kremlin sees its foreign policy star on rise», Radio Free Europe/Radio Liberty (RFE/ RL), 21 de Março de 2007. [www.rferl.org/featuresarticle/2007/03/2e6ae5fc-18c5-4150-85a291dde1e4e823.html]. 
Russian Military Doctrine (1993) The Basic Provisions of the Military Doctrine of the Russian Federation, Edict 1833 of the President of the Russian Federation, 2 de Novembro. [http:// www.fas.org/nuke/guide/russia/doctrine/russia-mil-doc.html]

Russian Military Doctrine (2010) Approved by Presidential Decree, 5 de Fevereiro.

Sakwa, Richard (1998) Soviet Politics in Perspective, $2^{\mathrm{a}}$ ed. London: Routledge.

Sakwa, Richard (2005) "Perestroika and the Challenge for Democracy in Russia" Demokratizatsiya, 13(2), 173-191.

Shevtsova, Lilia (2005) Putin's Russia. Washington, D. C.: Carnegie Endowment for International Peace.

Schöpplin, George (2007) «Russia's Reinvented Empire», Open Democracy, 3 de Maio.

Slezneva, Ludmilla (2003) "Post-Soviet Russian Foreign Policy: Between Doctrine and Pragmatism», in Rick Fawn (org.), Realignments in Russian Foreign Policy. London: Frank Cass, 10-28.

The Constitution of the Russian Federation (1993) com as emendas de 9 de Janeiro de 1996, 10 de Fevereiro de 1996 e 9 de Junho de 2001, 25 de Dezembro. [http://www.constitution.ru/]. 